\title{
Does testosteron have an effect on bone mineral density in postmenopausal women?
}

\author{
Arpaci Dilek ${ }^{1}$, Saglam Fatma ${ }^{2}$, Cuhaci Fatma Neslihan ${ }^{2}$, Ersoy Reyhan $^{3}$, Cakir Bekir $^{3}$ \\ 1Sakarya Education and Research Hospital, , Endocrinology and Metabolism Department \\ 2Ataturk Education and Research Hospital, , Endocrinology and Metabolism Department \\ 3Yildirim Beyazit Unuversity, Endocrinology and Metabolism Department
}

\begin{abstract}
Background: Osteoporosis is a common problem in postmenopausal women. There is limited data about the physiological importance of endogenous testosterone $(\mathrm{T})$ on bone mineral density (BMD) in older women is poorly understood.

Aim: The aim of this study was to evaluate association of endogeneous T with BMD and body mass index( BMI ).

Materials-methods: This cross-sectional study included 64 patients (45-85 year) postmenopausal women; their demographic features, BMD and serum total testosteron levels and relationship between T and BMD were evaluated. When the patients divided into three cathegories according to BMD; Group 1A: normal; Group 1B:osteopenic; Group 1C:osteoporotic (Table 1)
\end{abstract}

Results: Serum total testosterone levels were found not to be correlated with BMD. We didn't find any differences in serum testosterone levels between three BMD groups.

Conclusion: This study suggests that endogenous androgens are influential on bone density in postmenopausal women. However, we didn't find any relationship. Effects of endogenous testosterone level on BMD is controversial. 
Table 1. Demographic parameters and laboratory results of three groups.

\begin{tabular}{|l|l|l|l|l|}
\hline & $\begin{array}{l}\text { Group 1A } \\
(\mathrm{n}=22)\end{array}$ & $\begin{array}{l}\text { Group 1B } \\
(\mathrm{n}=21)\end{array}$ & $\begin{array}{l}\text { Group 1C } \\
(\mathrm{n}=21)\end{array}$ & P-value \\
\hline Age (years) & $54 \pm 6.3$ & $56 \pm 7.9$ & $58 \pm 1.0$ & 0.058 \\
\hline Menopausal age & $46 \pm 4.0$ & $44 \pm 5.4$ & $43 \pm 6.6$ & 0.131 \\
\hline Height (cm) & $158 \pm 6.2$ & $1.58 \pm 4.9$ & $155 \pm 6,1$ & 0.304 \\
\hline Weight (kg) & $75 \pm 13.4$ & $71 \pm 15.0$ & $68 \pm 12.5$ & 0.383 \\
\hline BMI (kg/m $\left.{ }^{2}\right)$ & $30.5 \pm 5.1$ & $28 \pm 5.3$ & $27.6 \pm 4.3$ & 0.450 \\
\hline Calcium (mg/dl) & $9.45 \pm 0.56$ & $9.40 \pm 0.42$ & $9.40 \pm 0.57$ & 0.984 \\
\hline Phosphorus & $3.7 \pm 0.79$ & $3.6 \pm 0.59$ & $3.5 \pm 0.48$ & 0.684 \\
$($ mg/dl) & & & & 0.712 \\
\hline Albumin (g/dL) & $4.4 \pm 0.31$ & $4.3 \pm 0.40$ & $3.5 \pm 0.48$ & 0.933 \\
\hline PTH (pg/mL) & $55.1 \pm 2.98$ & $60 \pm 3.5$ & $43.6 \pm 1.37$ & 0.045 \\
\hline $25-$ OH D vit & $21.5 \pm 16.3$ & $24.8 \pm 13.8$ & $23.7 \pm 14.2$ & 0.986 \\
\hline Testosterone & $38.6 \pm 20.2$ & $27.1 \pm 14.7$ & $28.6 \pm 19.2$ & \\
\hline (ng/dL) & & & & \\
\hline
\end{tabular}

